\title{
Factors associated with unintended pregnancy among women attending a public health facility in KwaZulu-Natal, South Africa
}

\author{
Firoza Haffejee ${ }^{a *}$ (D), Laura O'Connorb, Nalini Govendera, Poovendhree Reddyc, Maureen Nokuthula Sibiyad (D), Shanaz Ghumanc, \\ Thembelihle Ngxongo ${ }^{e}$ and Dorinda Borg ${ }^{b}$
}

\author{
${ }^{a}$ Department of Basic Medical Sciences, Durban University of Technology, Durban, South Africa \\ ${ }^{b}$ Department of Chiropractic and Somatology, Durban University of Technology, Durban, South Africa \\ 'Department of Community Health Studies, Durban University of Technology, Durban, South Africa \\ ${ }^{d}$ Faculty of Health Sciences, Durban University of Technology, Durban, South Africa \\ 'Department of Nursing, Durban University of Technology, Durban, South Africa \\ *Corresponding author, email: firozah@dut.ac.za
}

Background: Across the globe a large proportion of pregnancies have been reported as unintended. There are no available reports from South Africa concerning the prevalence of unintended pregnancies. This study explored the prevalence of unintended pregnancies among South African women attending a public primary health care (PHC) clinic in KwaZulu-Natal (KZN), South Africa. It also investigated the relationship between demographic factors, contraceptive use, substance abuse and unintended pregnancy in this setting.

Methods: A descriptive cross-sectional survey was conducted among patients $(n=328)$ attending a PHC clinic. Participants were recruited by convenience sampling. Women who attended the clinic on their first antenatal visit were invited to participate. Participants filled out questionnaires in either English or isiZulu. Association between pregnancy and categorical variables was assessed.

Results: Participants were mostly single (89.9\%; $n=267)$, unemployed $(70.8 \% ; n=222)$ with a monthly income of less than $\mathrm{R} 1$ 500 per month $(63.8 \% ; n=81)$. Two-thirds of the women $(64.33 \% ; n=211)$ had unintended pregnancies. There was a significant relationship between marital status and unintended pregnancy. Women who were married or living with their partners were more likely to have planned their pregnancies as compared with those who were single or divorced. Unemployed women were more likely to have had unintended pregnancies. No other socio-demographic factors were linked to unintended pregnancy. Conclusion: It is concluded that in this population of South African women with low education levels and low income, the prevalence of unintended pregnancies is high. These unintended pregnancies are linked to single status as well as unemployment.

Keywords: pregnancy, public sector health care, South Africa, unintended pregnancy

\begin{abstract}
Introduction
Unintended pregnancies are those that are not wanted by both parents or mistimed at the time of conception. ${ }^{1,2}$ Approximately 86 million pregnancies in 2008 were unintended, with 74 million of these occurring in less developed countries. ${ }^{1}$ Moreover, $39 \%$ of unintended pregnancies resulted in live births, $48 \%$ in abortions and $13 \%$ in miscarriages. ${ }^{1}$ Unintended pregnancy is a major public health burden, because it is linked with negative health, social and economic consequences. ${ }^{1,3}$ Studies have shown that approximately $28 \%$ of unintended pregnancies in developing countries can be avoided. ${ }^{4}$ Planned or intended pregnancies empower women to improve decision-making regarding antenatal care (ANC), prenatal diagnosis and use of folic acid, and prevent exposure to teratogenic substances, thus enhancing the health and growth of the developing child. ${ }^{5}$
\end{abstract}

The risk of unintended pregnancy in sub-Saharan Africa remains high and is poorly resolved due to poor access to reproductive health care. ${ }^{6}$ In Botswana $44 \%$ of pregnancies are reported to be unintended. ${ }^{7}$ Although recent reports indicate that the rate of unintended pregnancies in South Africa is high, these reports do not provide the frequencies of these pregnancies. ${ }^{8}$ The 1998 South Africa demographic and health survey reported $61 \%$ and $46 \%$ unintentional first and second pregnancies, respectively, within South Africa. ${ }^{9}$ In addition, studies conducted in KwaZuluNatal (KZN), South Africa, suggest that $84 \%$ of all pregnancies were unintended..$^{10}$ It is important that more recent data be obtained in order to ascertain whether any changes in pregnancy intention have occurred in the last decade.

Unintended pregnancies have been attributed to poor family planning and/or inadequate access to contraceptives, religious beliefs, inadequate understanding of contraception and reproductive health education, lack of inter-partner communication and sexual violence. ${ }^{11-16}$ Communication between partners with regard to family planning is related to the use of contraceptives and thus the prevention of unintended pregnancies. ${ }^{17}$ This is supported by Exavery et al. (2014), who suggest that single marital status is a risk factor for unintended pregnancies. ${ }^{18}$ Moreover, Font-Ribera et al. (2008) report that single women as well as those from disadvantaged socioeconomic environments are more at risk of having an unintended pregnancy. ${ }^{5}$ Socio-economic inequalities may therefore affect a women's ability to plan pregnancies, based on the resources available for raising a child.

Moreover, risky behaviours such as alcohol abuse and smoking may lead to unintended pregnancies. ${ }^{19,20}$ Such health-risk behaviours predispose both the mother and the developing foetus to adverse pregnancy and neonatal outcomes.

Based on the current knowledge of the risks related to unintended pregnancies and the scarcity of such studies in South Africa, this study aimed at exploring the factors associated 
with unintended pregnancies among South African women attending a public primary health care clinic in KwaZulu-Natal (KZN), South Africa. This study is valuable as little is known about the relationship between demographic factors, contraceptive use, substance abuse and unintended pregnancy in this setting.

\section{Methods}

This was a descriptive cross-sectional survey, utilising a sociodemographic questionnaire as well as clinic records of recruited participants. The study was conducted from October 2015 to October 2016 at a primary health care (PHC) clinic in the eThekwini Municipality of KZN, South Africa. Women presenting at the clinic for the first time for ANC, between two and 30 weeks of pregnancy, were invited to participate. The average number of women that present for the first ANC visit annually is 1800 . Using this total population, a confidence level of $95 \%$ and a confidence interval of 5\%, the required minimum sample size was 317 .

Participants were recruited by convenience sampling. Women who came to the clinic on their first antenatal visit were informed about the study by the research nurse and were invited to participate. Participation was voluntary and no one was coerced into answering the questionnaire. Women were excluded if they were too sick to participate or suffering from mental illness. After obtaining written informed consent, a total of 328 women completed two surveys and were examined by the clinic nurse, who extracted additional data from their clinic file. The surveys were available in isiZulu or English.

A socio-demographic questionnaire, by Napier et al. (2009) was utilised to obtain information pertaining to the participant's

Table 1: Participant demographics $(n=328)$

\begin{tabular}{|c|c|}
\hline Variables & Total $\boldsymbol{n}(\%)$ \\
\hline \multicolumn{2}{|l|}{ Age } \\
\hline Under 18 yrs & $18(6.2)$ \\
\hline $18-30$ yrs & $220(74.8)$ \\
\hline$>30$ yrs & $56(19.0)$ \\
\hline \multicolumn{2}{|l|}{ Marital status } \\
\hline Married/living together & $53(16.3)$ \\
\hline Single & $267(81.9)$ \\
\hline Divorced/separated/widowed/other & $6(1.8)$ \\
\hline Contraception use & $205(75.4)$ \\
\hline Ever consumed alcohol & $109(34.4)$ \\
\hline Cigarette smoking & $3(0.95)$ \\
\hline Recreational drug use & $6(1.94)$ \\
\hline Currently employed & $92(29.3)$ \\
\hline \multicolumn{2}{|l|}{ Household income } \\
\hline Less than 1500 & $81(63.8)$ \\
\hline 1501 to 3000 & $28(22.0)$ \\
\hline$>3000$ & $19(15.0)$ \\
\hline Recipient of a government grant & $70(37.9)$ \\
\hline \multicolumn{2}{|l|}{ Level of education } \\
\hline None & $9(2.9)$ \\
\hline Primary school & $9(2.9)$ \\
\hline High school & $228(73.5)$ \\
\hline Post school & $64(20.6)$ \\
\hline HIV positive & $63(30.3)$ \\
\hline
\end{tabular}

household living arrangements, family resources, employment status, income and education. ${ }^{21}$ Obtaining socio-demographic data assists in establishing the social and economic conditions that affect an individual and can be used to establish poverty levels. ${ }^{22}$ The researchers compiled a questionnaire to obtain information relative to contraceptive use, pregnancy and psychosocial factors relevant to pregnancy. This questionnaire was validated by a focus group, where each question was critically analysed and modified or removed if necessary. Prior to starting the study both questionnaires were pilot tested to ensure that the surveys were easy to administer and that there was no ambiguity in answering the questions.

A chart review tool was developed to extract pregnancy and health-related information from the participants' clinic charts. All data were collected on the participant's first antenatal visit. Ethical approval to conduct the study was obtained from the Institutional Research Ethics Committee of Durban University of Technology (Ref: IREC 34/14 and IREC 045/14), eThekwini Health District and KZN Provincial Department of Health (Ref: HRKM 234/14).

\section{Statistical analysis}

Statistical analysis was conducted using STATA ${ }^{\oplus}$ version 11 (StataCorp LLC, College Station, TX, USA). Data were analysed using both descriptive and inferential statistics. Frequency distributions of categorical variables, means, standard deviation and ranges of continuous variables were calculated. Association between intended pregnancy and categorical variables was assessed using the chi-square or Fisher's exact test, where applicable. For numerical data, independent Student t-tests were utilised. Multivariate regression modelling was done using a backward stepwise method with the inclusion of relevant covariates. Odds ratio were calculated for binary outcome variables. Confidence intervals (95\%) were calculated and a $p$-value less than 0.05 was considered statistically significant.

\section{Results}

A total of 328 pregnant women were enrolled in the study. Their mean age was $26 \pm 5.8$ years, ranging from 15 to 44 years of age. Their demographic, psychosocial and pregnancy-related characteristics are highlighted in Table 1 . They were mostly single (89.9\%; $n=267)$, unemployed $(70.8 \% ; n=222)$ with a monthly income of less than R1 500 per month $(63.8 \% ; n=81)$. The mean gestational age at the time of enrolment was $13.8 \pm 5.12$ weeks with a range from two to 30 weeks. A third of the women $(35.7 \%$; $n=117$ ) intended to continue their pregnancy yet $75.4 \%$ $(n=205)$ reported having been using contraceptives. According to the clinical records, the majority of the women were not HIV positive $(69.7 \% ; n=145)$. Only $34.4 \%(n=109)$ indicated that they had ever drunk alcohol.

Bivariate analysis showed that there was a significant relationship between marital status and unintended pregnancy, with those who were married or living with their partners more likely to have planned their pregnancy than those who were single or divorced $(p<0.001)$. Those who were currently unemployed were more likely to have had unintended pregnancies $(p=0.020)$, as seen in Table 2. No significant relationships were found between age, household income, being a recipient of a government grant or level of education and unintended pregnancy. HIV status did not affect the participants' pregnancy intention. There was a significant relationship between not using contraception by those who had unintended pregnancies and reporting that they thought they could not get pregnant $(p<0.001)$. No significant 
Table 2: Demographic, psychosocial and pregnancy-related variables relative to intended and unintended pregnancy $(\boldsymbol{n}=328)$

\begin{tabular}{|c|c|c|c|}
\hline Variables* & Intended $\boldsymbol{n}(\%)$ & $\begin{array}{l}\text { Unintended } \\
\qquad n(\%)\end{array}$ & $p$-value \\
\hline Age & & & 0.09 \\
\hline Under 18 yrs & $4(1.4)$ & $14(4.8)$ & \\
\hline $18-30$ yrs & $72(24.5)$ & $148(50.3)$ & \\
\hline$>30$ yrs & $26(8.8)$ & $30(10.2)$ & \\
\hline${ }^{*}$ Marital status & & & $<0.001$ \\
\hline Married/living together & $32(9.8)$ & $21(6.4)$ & \\
\hline Single & $84(25.8)$ & $183(56.1)$ & \\
\hline $\begin{array}{l}\text { Divorced/separated/wid- } \\
\text { owed/other }\end{array}$ & $1(0.3)$ & $5(1.5)$ & \\
\hline Contraception use & $72(26.5)$ & $133(48.9)$ & 0.371 \\
\hline \multicolumn{4}{|l|}{$\begin{array}{l}\text { Reasons for not using } \\
\text { contraception }\end{array}$} \\
\hline $\begin{array}{l}\text { *I didn't mind if I got } \\
\text { pregnant }\end{array}$ & $63(24.5)$ & $28(10.9)$ & $<0.001$ \\
\hline $\begin{array}{l}{ }^{*} \text { I thought I could not get } \\
\text { pregnant at that time }\end{array}$ & $14(5.4)$ & $80(31.1)$ & $<0.001$ \\
\hline $\begin{array}{l}\text { I had side effects from the } \\
\text { birth control method I was } \\
\text { using }\end{array}$ & $8(3.1)$ & $20(7.8)$ & 0.416 \\
\hline $\begin{array}{l}\text { I had problems getting } \\
\text { birth control when I needed } \\
\text { it }\end{array}$ & $0(0.0)$ & $4(1.6)$ & 0.301 \\
\hline $\begin{array}{l}\text { I thought my husband/ } \\
\text { partner or I was sterile }\end{array}$ & $2(0.8)$ & $3(1.2)$ & 1.000 \\
\hline $\begin{array}{l}\text { My husband or partner } \\
\text { didn't want to use anything }\end{array}$ & $2(0.8)$ & $5(1.9)$ & 1.000 \\
\hline Religious beliefs & $0(0.0)$ & $2(0.8)$ & 0.540 \\
\hline Other & $8(3.1)$ & $30(11.7)$ & 0.079 \\
\hline $\begin{array}{l}\text { Use of home remedies to } \\
\text { stop being pregnant }\end{array}$ & $0(0.0)$ & $1(0.5)$ & 0.331 \\
\hline *Ever consumed alcohol & $31(9.8)$ & $78(24.6)$ & 0.080 \\
\hline $\begin{array}{l}\text { Alcohol use } 3 \text { months prior } \\
\text { to pregnancy }\end{array}$ & $16(6.3)$ & $33(12.9)$ & 0.744 \\
\hline $\begin{array}{l}\text { Alcohol consumption while } \\
\text { pregnant }\end{array}$ & $6(2.2)$ & $5(1.9)$ & 0.210 \\
\hline Cigarette smoking & $4(1.4)$ & $2(0.8)$ & 0.668 \\
\hline Recreational drug use & $1(0.35)$ & $2(0.8)$ & 0.283 \\
\hline${ }^{*}$ Currently employed & $42(13.4)$ & $50(15.9)$ & 0.020 \\
\hline Household income & & & 0.122 \\
\hline Less than 1500 & $26(20.5)$ & $55(43.3)$ & \\
\hline 1501 to 3000 & $10(7.9)$ & $18(14.2)$ & \\
\hline$>3000$ & $11(8.7)$ & $8(6.3)$ & \\
\hline $\begin{array}{l}\text { Recipient of a government } \\
\text { grant }\end{array}$ & $21(11.4)$ & $49(26.5)$ & 0.271 \\
\hline Level of education & & & 0.437 \\
\hline None & $2(0.6)$ & $7(2.3)$ & \\
\hline Primary school & $2(0.6)$ & $7(2.3)$ & \\
\hline High school & $77(24.8)$ & $151(48.7)$ & \\
\hline Post school & $27(8.7)$ & $37(11.9)$ & \\
\hline HIV positive & $21(10.1)$ & $42(20.2)$ & 0.898 \\
\hline
\end{tabular}

${ }^{*} p$-value $<0.05$; there were missing data for some of the variables.
Table 3: Multivariate logistic regression of unintended pregnancy by marital status, alcohol used during pregnancy and beneficiary of a government and/or child grant

\begin{tabular}{|c|c|c|c|}
\hline \multirow[t]{2}{*}{ Variable } & \multicolumn{3}{|c|}{ Unintended pregnancy** } \\
\hline & OR & $95 \% \mathrm{Cl}$ & $p$-value \\
\hline \multicolumn{4}{|l|}{ Marital status } \\
\hline Married & 1.00 & & \\
\hline *Single & 3.73 & $1.82-7.62$ & $<0.001$ \\
\hline Divorced & 3.08 & $0.25-37.25$ & 0.377 \\
\hline No alcohol use & 1.00 & & \\
\hline $\begin{array}{l}\text { Alcohol used prior to } \\
\text { pregnancy }\end{array}$ & 0.94 & $0.46-1.92$ & 0.871 \\
\hline $\begin{array}{l}\text { Alcohol during } \\
\text { pregnancy }\end{array}$ & 0.27 & $0.64-1.17$ & 0.081 \\
\hline No grants & 1.00 & & \\
\hline Government grants & 1.24 & $0.62-2.47$ & 0.549 \\
\hline Child grants & 1.18 & $0.62-2.25$ & 0.612 \\
\hline
\end{tabular}

* Model adjusted for alcohol use before pregnancy and level of education.

** $p$-value $<0.05$.

relationships were found between the use of home remedies to stop pregnancy, reported history of alcohol use, use of alcohol in the three months prior to falling pregnant or alcohol use while pregnant and unintended pregnancy. There was also no relationship between cigarette smoking and illicit drug use versus unintended pregnancy (see Table 2).

Multivariate analysis, controlling for alcohol use prior to pregnancy, and level of education showed that single pregnant participants were $3.73(1.82-7.62)$ times more likely to have reported that their pregnancy was unintended, with no other significant relationships being found (Table 3 ).

\section{Discussion}

This study ascertained factors that influence unintended pregnancy in women attending a public healthcare facility in KwaZulu-Natal, South Africa. Our results show that there is a high prevalence of unintended pregnancies in the study population, with only $36 \%$ reporting that they wanted the pregnancy. Unintended pregnancies were more common in single women and those who were not employed, with no other demographic or behavioural characteristics having an effect on pregnancy intention.

Our finding of approximately two-thirds (64.33\%) of the pregnancies being unintended is consistent with reports from studies conducted in America and Ghana. ${ }^{6,23}$ Reports from Tanzania estimate that about half of the pregnancies in that country are unintended. ${ }^{18}$ In contrast, pregnancy intention is high in the Chinese population, where more than $72 \%$ of the pregnancies were intended. ${ }^{24}$

The findings from the current study demonstrate that women with unintended pregnancies were more likely to be single compared with women whose pregnancies were intended. It must be noted that the proportion of single status within the study population was high, with a total of $82 \%$ of women being single. This is consistent with findings of high single status 
among women from peri-urban areas in South Africa. ${ }^{25}$ The high rate of unwanted pregnancies among single women is corroborated by studies in both American and other African populations ${ }^{6,18,26-28}$ Researchers have argued that single women are more likely to engage in sexual activity for reasons other than child bearing. ${ }^{18}$ Moreover, an absence of inter-partner communication regarding pregnancy is reported to raise the risk of unintended pregnancies. ${ }^{27}$ Furthermore, this is reported to delay prenatal care. ${ }^{29}$ Our finding, that most of the women commenced prenatal care in the second semester, supports this. It must, however, be noted that traditional prenatal care programmes implemented in developed countries have been ineffective in developing countries, including South Africa, where prenatal care has been modified to the basic antenatal care approach, which requires women to report for their first antenatal visit prior to 20 weeks of gestation. ${ }^{30}$

Although bivariate analysis indicates a relationship between pregnancy intention and employment, we do not show a relationship between pregnancy intention and level of income. This is possibly due to the majority of women in the present study having a low level of income. Being single and with limited financial resources has the consequence of economic instability and thus difficulty to support a family. Furthermore, women with low income have higher rates of unintended pregnancies than those from higher income brackets and this could be related to poorer women using contraceptives infrequently and experiencing higher rates of contraceptive failure. ${ }^{27}$ Moreover, previous reports from low-income groups within the same geographic region have shown that women have difficulty in negotiating condom use with their male partners. ${ }^{31,32}$ Such difficulty will lead to infrequent condom use and thus the high level of unintended pregnancies.

Our data showed no correlation between intention of pregnancy and education levels, but this may be related to the majority of the women having only some form of secondary education and nothing further. In contrast, pregnancy intention was inversely correlated with education levels in other African countries. ${ }^{28}$ Furthermore, lower levels of education are associated with increased pregnancy in single women, irrespective of the pregnancy being planned or unplanned. ${ }^{26}$

There was no relationship between pregnancy intention and contraceptive use. Over a third $(36.6 \%)$ of the women reported that they thought they could not get pregnant. Thus, misconceptions regarding fertility and contraceptive use are prevalent. It is likely that contraceptive use was inconsistent as some women $(19.5 \% ; n=64)$ who reported using contraceptives also provided reasons for not using them. This finding is consistent with a recent report that perceptions of low fertility lead to inconsistent contraceptive use..$^{33}$ The latter report also indicates that prior sexual intercourse without pregnancy may lead to the assumption of subfertility and hence contraceptive non-use or inconsistent use..$^{33}$

Previous studies have also linked unwanted pregnancies with alcohol and illicit drug use as well as cigarette smoking. . $^{23,34,35}$ However, this relationship was not found in the current study, possibly due to low levels of smoking (0.95\%) and use of illicit drugs (1.94\%) in the study population. This is consistent with other studies of South African pregnant women from the same background, which also indicated little or no substance abuse amongst these women. ${ }^{36}$ Although over a third (34.4\%) of the women had ever consumed alcohol, we found no relationship between alcohol use and pregnancy intention $(p=0.08)$.

Unintended pregnancies contribute to unwanted population growth, subsequently compromising social services. Thus, the elimination of unintended pregnancies will enhance the wellbeing of women and their families. We suggest a need to improve the knowledge of contraception and family planning methods within this population, so that women are able to control their fertility and determine when to have children.

We conclude that in this population of South African women with low education levels and low income, the prevalence of unintended pregnancies is high and that this is linked to single status.

Acknowledgements - The authors thank Charity Wendy Nare, Charlene Singh and Deseree Rajpal for assisting with administration and coordination of the project. They also thank the nursing staff at the PHC facility for assistance with participant recruitment and data collection. They are grateful to all the patients who participated in the study.

Funding - The research was funded by the SA Medical Research Council (grant number DUT/MH1).

\section{Disclosure statement}

No potential conflict of interest was reported by the authors.

\section{ORCID}

Firoza Haffejee (iD) http://orcid.org/0000-0002-3908-8949 Maureen Nokuthula Sibiya (iD http://orcid.org/0000-0003-12201478

\section{References}

1. Singh S, Sedgh G, Hussain R. Unintended pregnancy: worldwide levels, trends, and outcomes. Stud Fam Plann. 2010;41(4):241-50. https://doi.org/10.1111/sifp.2010.41.issue-4

2. Chauke L. Unwanted pregnancy-a review of contraception: clinical. Prof Nurs Today. 2007;11(1):10-4.

3. Dixit P, Ram F, Dwivedi LK. Determinants of unwanted pregnancies in India using matched case-control designs. BMC Pregnancy Childbirth. 2012;12(1):84. https://doi.org/10.1186/1471-2393-12-84

4. Ali MM, Cleland J, Shah IH. Condom use within marriage: a neglected HIV intervention. Bull W H 0. 2004;82(3):180-86.

5. Font-Ribera L, Pérez G, Salvador J, et al. Socioeconomic inequalities in unintended pregnancy and abortion decision. J Urban Health. 2008;85(1):125-35. https://doi.org/10.1007/s11524-007-9233-z

6. Eliason S, Baiden F, Yankey BA, et al. Determinants of unintended pregnancies in rural Ghana. BMCPregnancy Childbirth.2014;14(1):261. https://doi.org/10.1186/1471-2393-14-261

7. Mayondi GK, Wirth K, Morroni C, et al. Unintended pregnancy, contraceptive use, and childbearing desires among HIV-infected and HIV-uninfected women in Botswana: across-sectional study. BMC Public Health. 2016;16(1):44.

8. Seutlwadi L, Peltzer K, Mchunu G, et al. Contraceptive use and associated factors among South African youth (18-24 years): a population-based survey. S Afr J Obstet Gynaecol. 2012;18(2):43-7.

9. Department of Health. South Africa demographic and health survey 1998. Full report: Department of Health (RSA) Pretoria. 2002.

10. Rochat TJ, Richter LM, Doll HA, et al. Depression among pregnant rural South African women undergoing HIV testing. J Am Med Assoc. 2006;295(12):1373-78. https://doi.org/10.1001/jama.295.12.1376

11. Goicolea I, San Sebastian M. Unintended pregnancy in the amazon basin of Ecuador: a multilevel analysis. Int J Equity Health. 2010;9(1):14 https://doi.org/10.1186/1475-9276-9-14 
12. Glasier A, Gülmezoglu AM, Schmid GP, et al. Sexual and reproductive health: a matter of life and death. The Lancet. 2006;368(9547):15951607. https://doi.org/10.1016/S0140-6736(06)69478-6

13. Rosenfeld JA, Everett KD. Factors related to planned and unplanned pregnancies. J Fam Pract. 1996;43(2):161-67.

14. Amin Shokravi F, Howden Chapman P, Peyman N. Comparison study: risk factors of unplanned pregnancies in a Group of Iranian and New Zealander Women. Eur J Sci Res. 2009;26(1):108-21.

15. Cheng D, Schwarz EB, Douglas E, et al. Unintended pregnancy and associated maternal preconception, prenatal and postpartum behaviors. Contraception. 2009;79(3):194-98. https://doi. org/10.1016/j.contraception.2008.09.009

16. Khajehpour M, Simbar M, Jannesari $S$, et al. Health status of women with intended and unintended pregnancies. Public Health. 2013;127(1):58-64. https://doi.org/10.1016/j.puhe.2012.08.011

17. Kamal SM, Islam MA. Interspousal communication on family planning and its effect on contraceptive adoption in Bangladesh. Asia Pac J Public Health. 2012;24(3):506-21.https://doi.org/10.1177/1010539511399118

18. ExaveryA,KantéAM,NjoziM,etal.Predictorsofmistimed,andunwanted pregnancies among women of childbearing age in Rufiji, Kilombero, and Ulanga districts of Tanzania. Reprod Health. 2014;11(1):63. https://doi.org/10.1186/1742-4755-11-63

19. O'Leary CM, Bower C. Guidelines for pregnancy: what's an acceptable risk, and how is the evidence (finally) shaping up? Drug Alcohol Rev. 2012;31(2):170-83. https://doi.org/10.1111/dar.2012.31.issue-2

20. Reardon DC, Coleman PK, Cougle JR. Substance use associated with unintended pregnancy outcomes in the national longitudinal survey of youth. The Am J Drug Alcohol Abuse. 2004;30(2):369-83. https://doi.org/10.1081/ADA-120037383

21. Napier C, Oldewage-Theron W, Kearney J. Comparison of three school feeding strategies for primary school children in an informal settlement in Gauteng, South Africa. Health SA Gesondheid. 2009;14(1):1-8.

22. Joubert G, Ehrlich R, Katzenellenbogen J, et al. Epidemiology: a research manual for South Africa. Cape Town: Oxford University Press Southern Africa; 2007.

23. Orr ST, James SA, Reiter JP. Unintended pregnancy and prenatal behaviors among urban, black women in Baltimore, Maryland: the Baltimore preterm birth study. Ann Epidemiol. 2008;18(7):545-51. https://doi.org/10.1016/j.annepidem.2008.03.005

24. Qian X, Tang S, Garner P. Unintended pregnancy and induced abortion among unmarried women in China: a systematic review. BMC Health Serv Res. 2004;4(1):1. https://doi.org/10.1186/1472-6963-4-1
25. Statistics South Africa. Gender statistics in South Africa 2011. Pretoria: Stats SA; 2011.

26. Musick K. Planned and unplanned childbearing among unmarried women. J Marriage Fam. 2002;64(4):915-29. https://doi.org/10.1111/ j.1741-3737.2002.00915.x

27. Finer LB, Henshaw SK. Disparities in rates of unintended pregnancy in the United States, 1994 and 2001. Perspect Sex Reprod Health. 2006;38(2):90-6. https://doi.org/10.1363/3809006

28. Palamuleni ME, Adebowale AS. Prevalence and determinants of unintendedpregnanciesinMalawi.AfrPopulationStud.2014;28(1):551. https://doi.org/10.11564/28-1-507

29. Dott M, Rasmussen SA, Hogue CJ, et al. Association between pregnancy intention and reproductive-health related behaviors before and after pregnancy recognition, national birth defects prevention study, 1997-2002. Matern Child Health J. 2010;14(3):37381. https://doi.org/10.1007/s10995-009-0458-1

30. Ngxongo TSP, Sibiya MN, Gwele NS. Experiences and views of the pregnant women regarding the Basic Antenatal Care approach to health care services provision in eThekwini district, KwaZulu-Natal. Res Rev: J Nurs Health Sci. 2016;3(1):5-14.

31. Ports KA, Haffejee $F$, Mosavel $M$, et al. Integrating cervical cancer prevention initiatives with HIV care in resource-constrained settings: a formative study in Durban, South Africa. Global Public Health 2015;10(10):1238-51. https://doi.org/10.1080/17441692.2015.1008021

32. Haffejee F, Ports KA, Mosavel M. Knowledge and attitudes about HIV infection and prevention of mother to child transmission of HIV in an urban, low income community in Durban, South Africa: Perspectives of residents and health care volunteers. Health SA Gesondheid. 2016;21:171-78. https://doi.org/10.1016/j.hsag.2016.02.001

33. Borrero S, Nikolajski C, Steinberg JR, et al."It just happens": a qualitative study exploring low-income women's perspectives on pregnancy intention and planning. Contraception. 2015;91(2):150-56. https://doi.org/10.1016/j.contraception.2014.09.014

34. Naimi TS, Lipscomb LE, Brewer RD, et al. Binge drinking in the preconception period and the risk of unintended pregnancy:implications for women and their children. Pediatrics. 2003;111(Supplement 1):113641.

35. Seggie J. Alcohol and South Africa's youth. S Afr Med J. 2012;102(7):587. https://doi.org/10.7196/SAMJ.6003

36. Haffejee F, Naicker T, Singh M, et al. Placental leptin in HIV-associated preeclampsia. Eur J Obstet Gynecol Reprod Biol. 2013;171(2):271-76. https://doi.org/10.1016/j.ejogrb.2013.09.027 